\title{
The Contribution of Excitatory Amino Acids to Central Sensitization and Persistent Nociception after Formalin-induced Tissue Injury
}

\author{
Terence J. Coderre ${ }^{1,2,3}$ and Ronald Melzack ${ }^{3}$ \\ ${ }^{1}$ Pain Mechanisms Laboratory, Clinical Research Institute of Montreal, ${ }^{2}$ Département de Médecine, Université de \\ Montréal, and ${ }^{3}$ Department of Psychology, McGill University, Montreal, Quebec, Canada
}

The contribution of excitatory amino acids (EAAs) to the development of central sensitization and persistent nociception in response to tissue injury in rats was examined following the subcutaneous injection of formalin into the hindpaw. Formalin-induced nociceptive behaviors were enhanced by intrathecal pretreatment with the EAAs L-glutamate and L-aspartate. An enhancement of the formalin nociceptive response was also produced by intrathecal pretreatment with the receptor-selective EAA agonists NMDA and trans-( \pm )-1-amino-1,3-cyclopentane dicarboyxlic acid (ACPD), but not $(R, S)$ - $\alpha$-amino-3-hydroxy-5-methylisozazole-4-propionic acid hydrobromide (AMPA). The effect of NMDA was enhanced by a combined administration with AMPA or APCD. Formalin nociceptive responses were dosedependently reduced by intrathecal pretreatment with the NMDA receptor antagonists 2-amino-5-phosphonovaleric acid (APV) and (+)-MK-801 hydrogen maleate, but not the selective AMPA antagonist 6-cyano-7-nitroquinoxaline-2,3dione or the selective metabotropic EAA receptor antagonist 2-amino-3-phosphonopropionic acid. The results suggest that EAAs acting at the NMDA receptor contribute to central sensitization and persistent nociception following subcutaneous formalin injection.

Increased pain in response to noxious stimulation following peripheral tissue injury depends on an increase in the sensitivity of primary afferent nociceptors at the site of injury (peripheral sensitization) (Bessou and Perl, 1969; Beitel and Dubncr, 1976), and on an increase in the excitability of neurons in the CNS (central sensitization) (Woolf, 1983; Coderre and Melzack, 1985). Central sensitization is triggered by inputs from nociceptive afferents and is associated with a reduced threshold of dorsal horn neurons to noxious stimulation (Perl, 1976; Price et al., 1978; Kenshalo et al., 1979), an expansion of the receptive fields of dorsal horn neurons (Cook et al., 1987; Hylden et al., 1989), a summation of slow postsynaptic potentials resulting in a cumulative depolarization and a prolonged afterdischarge or "windup" of dorsal horn neurons (Mendell, 1966), and an increased excitability of the flexion reflex in response to peripheral stimulation (Woolf, 1983; Woolf and Wall, 1986).

\footnotetext{
Received Nov. 27, 1991; revised Feb. 17, 1992; accepted Apr. 15, 1992

This work was supported by grants from the Medical Research Council of Canada (MT-1 1045) and Fonds de la Recherche en Santé du Québec (900051) to T.J.C., and a Natural Sciences and Engineering Research Council grant (A7891) to R.M.

Correspondence should be addressed to Terence J. Coderre, Ph.D., Director, Pain Mechanisms Laboratory, Clinical Research Institute of Montreal, 110 Pine Avenue West, Montreal, Quebec, Canada H2W 1R7.

Copyright (C) 1992 Society for Neuroscience $0270-6474 / 92 / 123665-06 \$ 05.00 / 0$
}

We have previously (Coderre et al., 1990) used the formalin test as a behavioral model of injury-induced central sensitization. Subcutaneous injection of dilute formalin into a rat's hindpaw produces a biphasic nociceptive response including an early intense response in the first $5 \mathrm{~min}$, and a later moderate response that is expressed from 20 to 60 min after injection (Dubuisson and Dennis, 1977; Wheeler-Aceto et al., 1990). It has been demonstrated that intrathecal administration of either lidocaine (Coderre et al., 1990) or the $\mu$-opiate DAMGO (Dickenson and Sullivan, 1987b) inhibits behavioral and dorsal horn neuron responses to subcutaneous formalin, if they are administered prior to, but not immediately after, the first phase of the formalin test. This suggests that neural activity generated during the early phase of the formalin response is capable of producing changes in CNS function (i.e., central sensitization), which in turn influence processing during the late phase.

The present study examines the neural mechanisms underlying central sensitization in response to subcutaneous formalin injection. Previous evidence implicates a contribution of excitatory amino acids (EAAs) to injury-induced sensitization in the dorsal horn. First, intrathecal administration of the EAAs L-glutamate or L-aspartate produces an increase in the excitability of flexor efferents (Woolf and Wiesenfeld-Hallin, 1986), while both competitive and noncompetitive NMDA antagonists reduce the facilitation of flexion reflexes induced by either brief electrical (C-fiber) stimulation or cutaneous application of the chemical irritant mustard oil (Woolf and Thompson, 1991). Second, repetitive C-fiber stimulation produces a "windup" of dorsal horn neuron activity that is mimicked by the application of L-glutamate (Zieglgansberger and Herz, 1971) and NMDA (King et al., 1988), and is blocked by application of either competitive (Dickenson and Sullivan, 1987a, 1990; Woolf and Thompson, 1991) or noncompetitive (Davies and Lodge, 1987; Woolf and Thompson, 1991) NMDA antagonists. Third, subcutaneous injection of formalin produces an increased release of glutamate and aspartate in spinal cord dorsal horn (Skilling et al., 1988). Fourth, sustained responses of spinal nociceptive cells to peripheral stimulation with formalin are reduced by selective NMDA antagonists (Haley et al., 1990).

The present study assessed the role of EAAs in the development of central sensitization and tonic nociception following subcutaneous formalin injection. Nociceptive behaviors, in response to an injection formalin into the hindpaw in rats, were assessed following intrathecal administration of agonists and antagonists to various EAA receptors. The results provide evidence that EAAs acting at the NMDA receptor, and probably also non-NMDA receptors (AMPA and metabotropic; see Mil- 
ler, 1991) contribute to central sensitization and tonic nociception following subcutaneous formalin injection.

\section{Materials and Methods}

The experiments were performed on $250-350 \mathrm{gm}$ male Long Evans hooded rats (Charles River). For nociccptive testing, rats were given either a standard subcutaneous injection of $50 \mu \mathrm{l}$ of $2.5 \%$ formalin or $30 \mu \mathrm{l}$ of a lower concentration $(1.0 \%)$ into the plantar surface of one hindpaw. Rats were then placed in a $30 \mathrm{~cm} \times 30 \mathrm{~cm} \times 30 \mathrm{~cm}$ Plexiglas box with a mirror below the floor at a $45^{\circ}$ angle to allow an unobstructed view of the paws. Observations for the purpose of generating nociceptive scores began immediately after formalin injection and were continued for $50 \mathrm{~min}$. A nociceptive score was determined for each $5 \mathrm{~min}$ block by measuring the amount of time spent in each of four behavioral categories: 0 , the injected paw is not favored; 1 , the injected paw has little or no weight on it; 2 , the injected paw is clevated and is not in contact with any surface; 3 , the injected paw is licked, bitten, or shaken. A weighted average nociceptive score, ranging from 0 to 3 , was calculated by multiplying the time spent in each category by the category weight, and then dividing by the total time for each 5 min time block.

Formalin nociceptive behavior was assessed in an observer-blind manner in 28 groups of rats following intrathecal administration of agonists and antagonists to various EAA receptors. In the first experiment, formalin nociceptive responses induced by a standard formalin injection were assessed in saline-treated control rats and rats that were administered the endogenous EAA agonists L-glutamate $(20 \mu \mathrm{g})$ and L-aspartate $(25 \mu \mathrm{g})$. This experiment was then repeated in rats given the lower concentration of formalin. In the next experiment, saline-treated rats were compared on nociceptive behaviors induced by a standard formalin injection with rats treated with the selective EAA receptor agonists $N$-methyl-D-aspartate (NMDA; $80 \mathrm{ng}$ ), $(R, S)$ - $\alpha$-amino-3-hydroxy-5-methylisozazole-4-propionic acid hydrobromide (AMPA; 50 ng), trans-( \pm )-1-amino-1,3-cyclopentane dicarboxylic acid (ACPD; 50 $\mathrm{ng}$ ), and combinations of NMDA (40 ng) and AMPA (25 ng) or NMDA $(40 \mathrm{ng})$ and ACPD (25 ng). Finally, formalin nociceptive responses were assessed in both control rats and rats treated with the EAA receptor antagonists 6-cyano-7-nitroquinoxaline-2,3-dione (CNQX; $100 \mathrm{ng}$ to $10 \mu \mathrm{g}$ ), 2-amino-3-phosphonopropionic acid (AP-3; $100 \mathrm{ng}$ to $10 \mu \mathrm{g}$ ), 2-amino-5-phosphonovaleric acid (APV; $500 \mathrm{ng}$ to $50 \mu \mathrm{g}$ ), and $(+)$ MK-801 hydrogen maleate (200 $\mathrm{ng}$ to $20 \mu \mathrm{g}$ ). All agents were dissolved in $0.9 \%$ saline and given $10-15$ min prior to testing as an intrathecal injection in a $20 \mu \mathrm{l}$ volume. In addition, the highest doses of APV and MK-801 were also each administered intrathecally to separate groups of rats as a postinjury treatment (i.e., $10 \mathrm{~min}$ after injection of formalin to the hindpaw).

Intrathecal injections were given by lumbar puncture between the L.4 and L5 vertebrae while the rats were under brief ether anesthesia. This involved a modification of the method used in mice by Hylden and Wilcox (1980), as performed by Papir-Kricheli et al. (1987). Dosages and timing of injections were based on those used by Aanonsen and Wilcox (1986, 1987). A single dose of each of the agonists was selected to in order produce mild nociceptive effects that would not produce behavioral responses that would interfere with formalin test ratings. Of the EAAs given, only NMDA and AMPA produced observable nociceptive behaviors. At the doses given, these agents produced mild nociceptive behaviors, including freezing and occasional flinching. Formalin injections were given after drug-induced nociceptive behaviors had subsided. The doses of some of the agents used matched those that produced greater nociceptive behaviors in other studies (Aanonsen and Wilcox, 1986, 1987). It is expected that this difference occurred because rats were anesthetized at the time of injection and did not experience the full immediate effects of these agents. It is also possible that the ether anesthesia produced sympathetic activation that interfered with nociceptive responses to these agents. In all cases, however, formalin injection and nociceptive testing did not commence until the rats had fully recovered from the ether anesthesia. Rats were killed immediately following testing by overdose with chloral hydrate. The experimental protocol was approved by the institutional animal care committee.

\section{Results}

Figure 1 illustrates the nociceptive responses for rats treated with saline, L-glutamate, and L-aspartate, for standard $(A)$ and low concentration $(B)$ formalin injections. In the standard test, the saline control group exhibited a typical biphasic nociceptive response with high scores in the first $5 \mathrm{~min}$, a reduction in responses for 10-15 min, and a subsequent increased level of nociceptive responses that started about $20 \mathrm{~min}$ after formalin injection and continued until the completion of testing. Nociceptive responses were significantly elevated in rats treated with either L-glutamate or L-aspartate (Fig. $1 A$ ). Importantly, intrathecal administration of these EAAs resulted in increased nociceptive responses only during the intermediate and late phases between 5 and $25 \mathrm{~min}$ after formalin injection. Nociceptive responses during the early phase of the formalin test were unaffected, indicating that the treatments did not simply produce an additive hyperalgesic effect. Rather, it appears that the EAA treatments shifted the tonic phase of the formalin test to an earlier time point, so that nociccptive responses during the normally quiet intermediate phase were more like those normally seen during the late phase of the formalin test. When the lower concentration of formalin was used, L-glutamate and $L$-aspartate produced elevations in formalin scores that lasted throughout the tonic (intermediate and late) phase of the formalin test (with the exception of a single time point at $40 \mathrm{~min}$ ) (Fig. $1 B$ ). This suggests that the late phase of the formalin response may have been inhibited by a ceiling effect that would have prevented nociceptive scores from rising to a significantly higher level than that seen in controls.

Figure 2 illustrates the formalin nociceptive responses for rats treated with selective EAA receptor agonists. Treatment with AMPA did not significantly affect nociceptive responses with respect to the saline-treated rats (Fig. $2 A$ ). On the other hand, treatment with NMDA or ACPD produced significant increases in formalin nociceptive responses between 5 and 10 or 5 and $15 \mathrm{~min}$ after formalin injection, respectively (Fig. $2 A, B$ ). Combinations of half the doses of NMDA and AMPA or NMDA and ACPD produced greater increases in nociceptive responses than that produced by the full dose of NMDA alone (Fig. $2 A, B$ ). These combinations produced effects that were similar to the potent effects of the endogenous agents L-glutamate and L-aspartate; in the case of NMDA + AMPA, the combination produced nociceptive responses that were significantly greater than the saline group throughout much of the testing period. Once again, the EAA agonists did not increase nociceptive responses during the early phase of the formalin test, indicating a shift in the tonic response rather than a general hyperalgesic effect.

Figure 3 illustrates the formalin nociceptive responses for rats treated with EAA antagonists. Formalin nociceptive responses were not significantly affected by the AMPA receptor antagonist CNQX (Fig. $3 A$ ) or the metabotropic EAA receptor antagonist AP-3 (Fig. 3B). In contrast, the selective NMDA receptor antagonists APV (Fig. 3C) and MK-801 (Fig. 3D) each produced a dose-dependent reduction in formalin nociceptive responses during the intermediate and late phases of the formalin test. It is significant that the NMDA antagonists did not lower nociceptive responses during the early phase, indicating that they did not produce a general analgesic effect, but rather they inhibited the development of tonic nociception following the normal expression of the early phase response. In addition, it is noteworthy that when NMDA receptor blockade was delayed until after the first phase of the formalin test was completed (APV or MK-801 after, Fig. 3C,D), its analgesic effects were lost. Aside from their analgesic effects, no behavioral side effects were observed with the antagonists used, except for a slight degree of hindlimb flaccidity with the highest dose $(20 \mu \mathrm{g})$ of 
$\mathbf{A}$

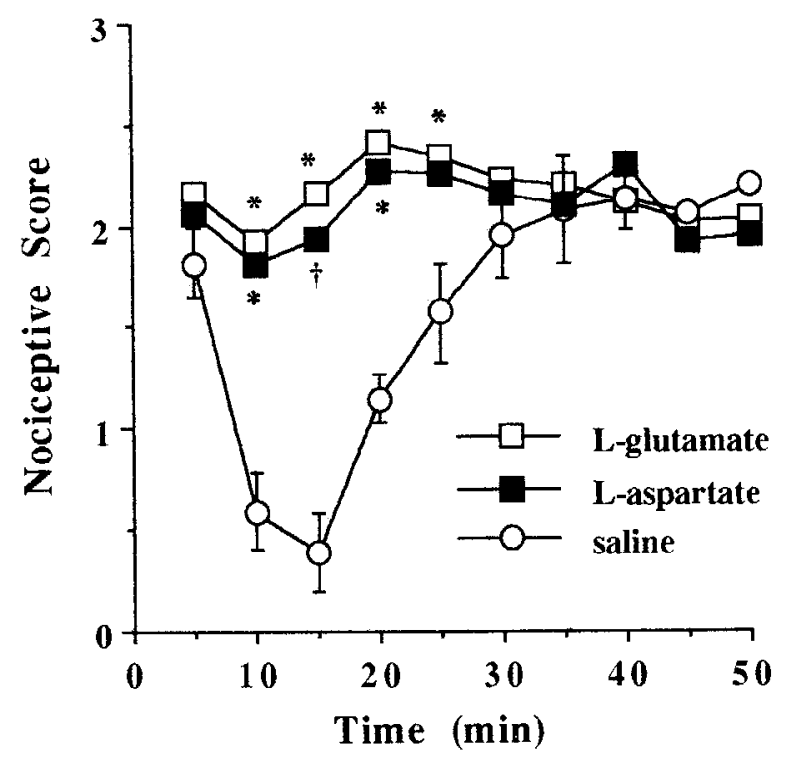

B

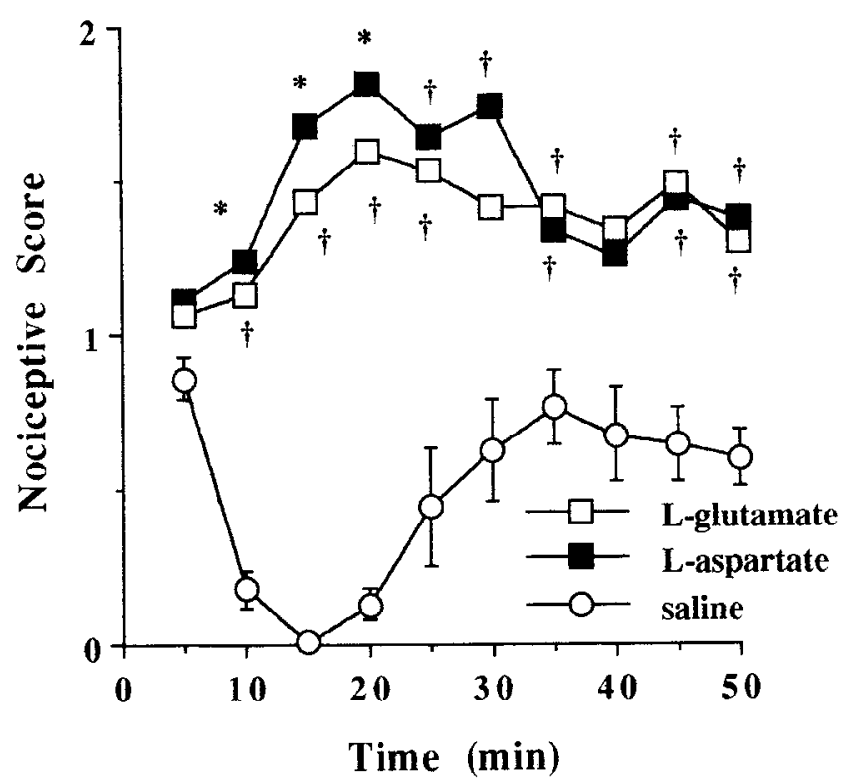

Figure 1. Nociceptive responses $( \pm \mathrm{SEM})$ to formalin injury for standard $(A)$ and low-concentration $(B)$ formalin-injected rats that were pretreated with intrathecal saline, L-glutamate $(20 \mu \mathrm{g})$, or L-aspartate $(25 \mu \mathrm{g})$. Statistical analyses performed in all experiments were nonparametric multiple comparisons to the control group (Zar, 1984) subsequent to Kruskal-Wallis analysis of ranks. Significant differences from the saline control group in this and subsequent figures are indicated by the following symbols: $\dagger, p<0.05 ;{ }^{*}, p<0.01$.

MK-801. This motor impairment could not account for the analgesia produced by MK-801 since the same dose that produced analgesia when given as a pretreatment was not effective when administered $10 \mathrm{~min}$ after formalin injection.

\section{Discussion}

The present study demonstrates that formalin-induced nociceptive behaviors are enhanced by pretreatment with the en-
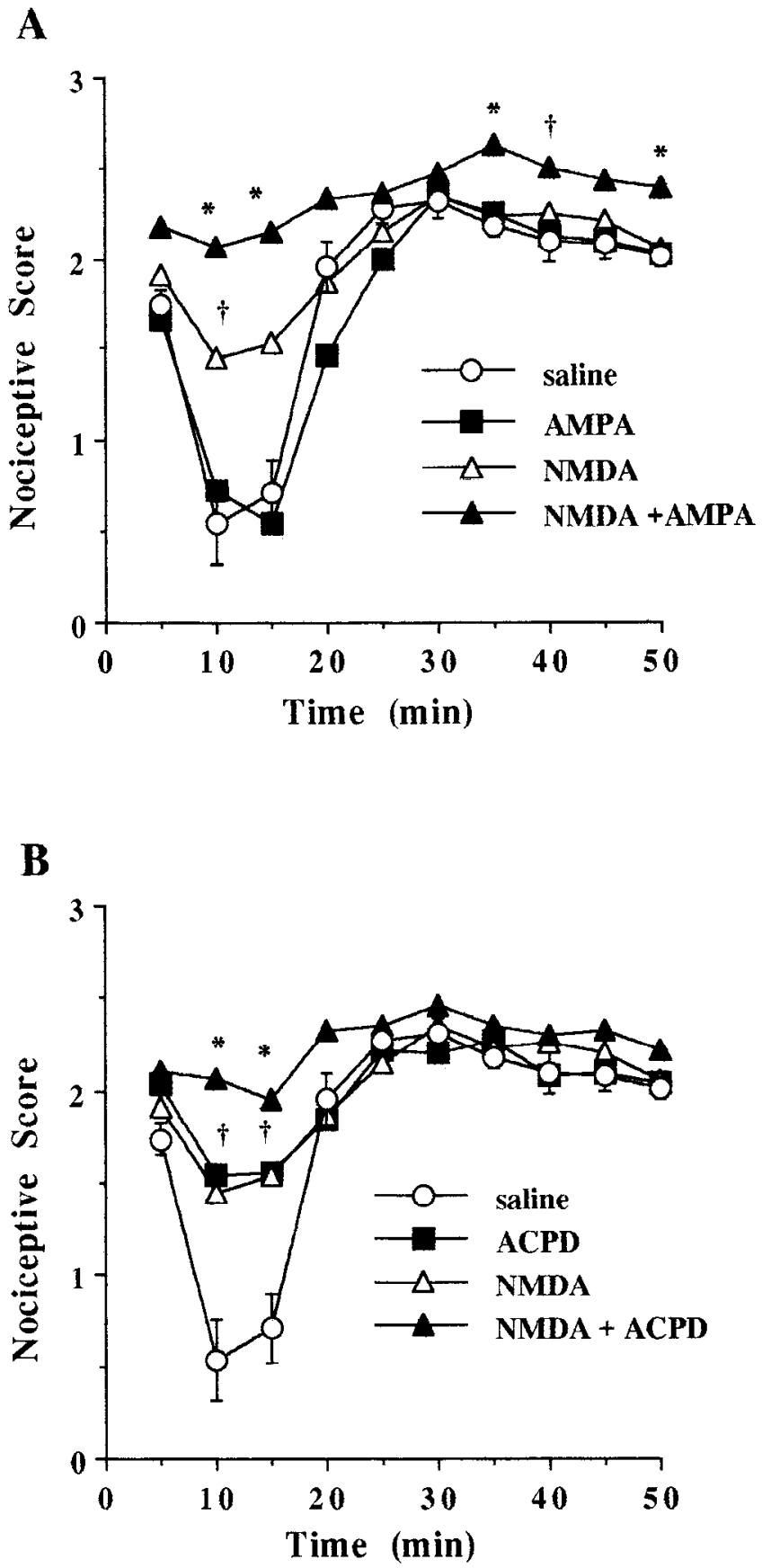

Figure 2. Nociceptive responses ( \pm SEM) to formalin injury in rats pretreated intrathecally with $A$ : saline, NMDA $(80 \mathrm{ng})$, AMPA $(50 \mathrm{ng})$, and NMDA (40 ng) + AMPA (25 ng); $B$ : saline, NMDA (80 ng), ACPD (50 ng), and NMDA (40 ng) + APCD (25 ng) (saline and NMDA groups are repeated in $A$ and $B$ ).

dogenous EAA agonists L-glutamate and L-aspartate. Thus, these data implicate a critical role of EAA receptors in the tonic response to a noxious chemogenic stimulus. Furthermore, the fact that formalin nociceptive responses are enhanced by NMDA and ACPD, but not AMPA, suggest that this effect is mediated by an action at either the NMDA or metabotropic EAA receptor, but not the AMPA receptor. However, it is noteworthy that combinations of half the doses of NMDA and AMPA or NMDA and ACPD produce a substantial increase in the effect, over that of the full dose of either agent alone, indicating that there may be an interactive effect of agonist actions at NMDA and both 
A CNQX

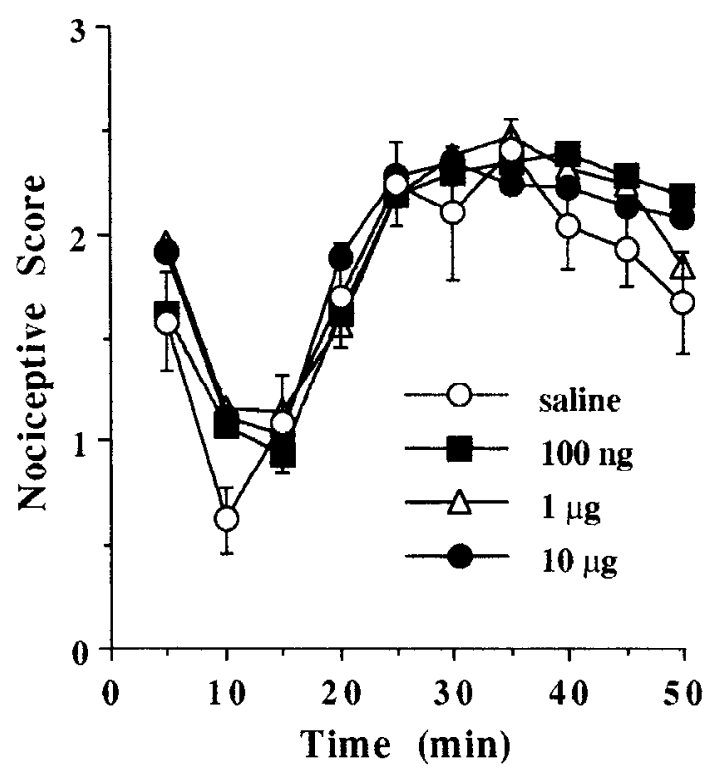

C APV

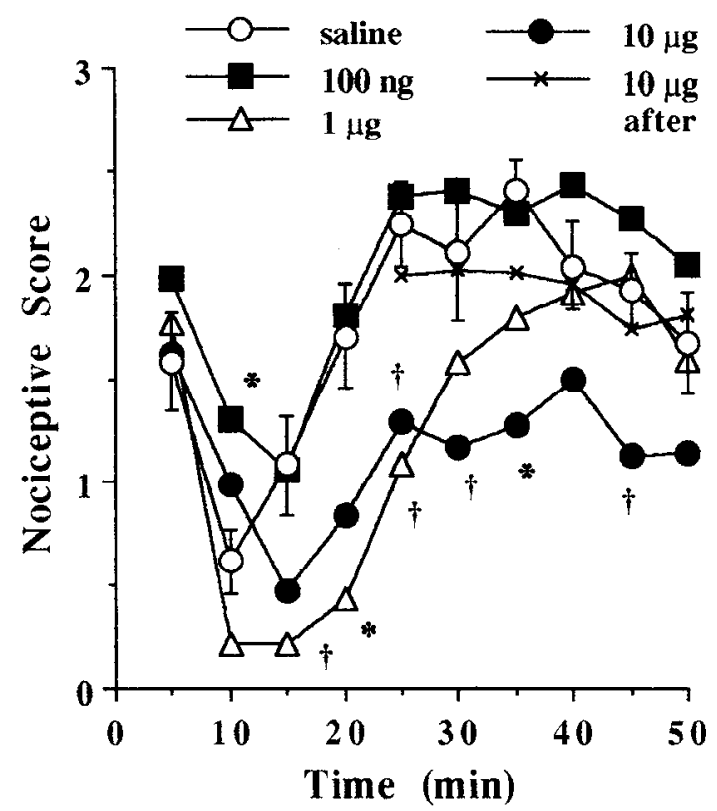

B AP-3

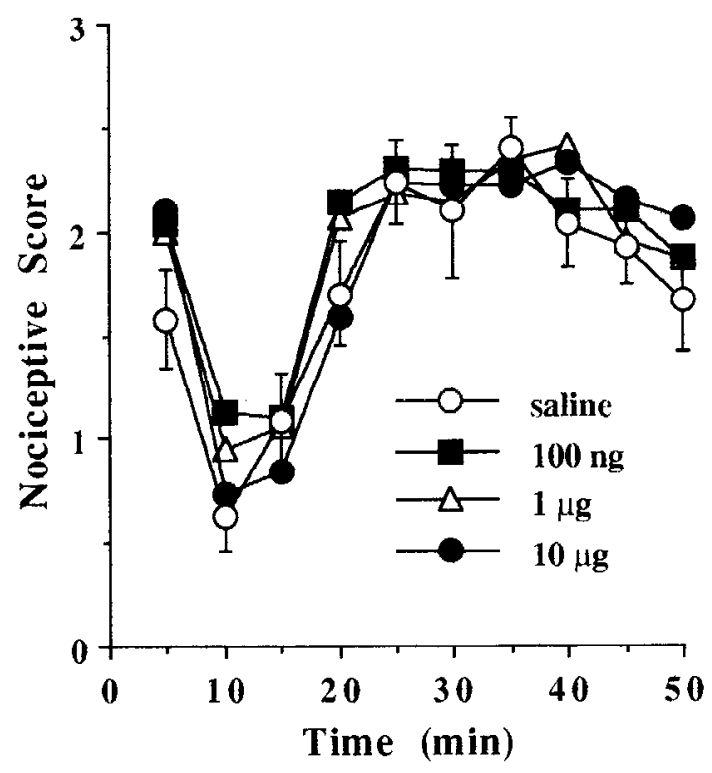

D MK-801

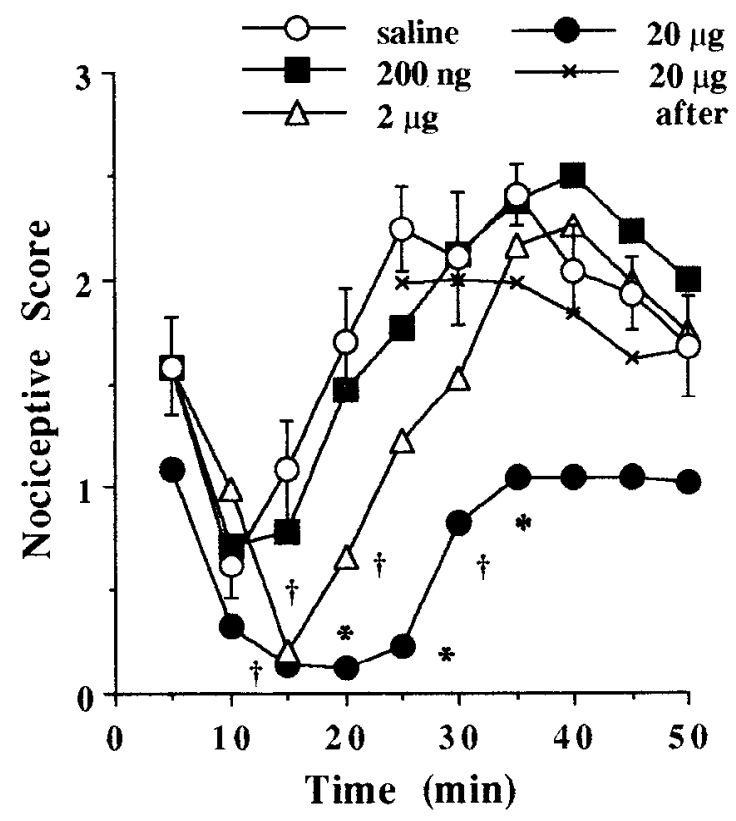

Figure 3. Nociceptive responses $( \pm \mathrm{SEM})$ to formalin injury in rats pretreated with intrathecal saline $(A-D), \mathrm{CNQX}(A), \mathrm{AP}-3(B), \mathrm{APV}(C)$, and MK-801 (D).

types of non-NMDA receptors. Activation of AMPA receptors may be required to reduce a voltage-dependent block of the NMDA receptor by extracellular $\mathrm{Mg}^{2+}$ (Mayer et al., 1984; Nowak et al., 1984). Furthermore, there may be an important interactive effect of agonists acting at NMDA and metabotropic EAA receptors.

Importantly, the EAA agonists increased nociceptive responses only in the tonic (intermediate and late) phase after formalin injection, but did not affect nociceptive responses dur- ing the early phase of the formalin test. It is unlikely that the early-phase responses were affected by a behavioral ceiling effect, since when rats were tested with a lower concentration of formalin, L-aspartate and L-glutamate pretreatment still failed to elevate early-phase responses significantly, despite their significant elevation of responses throughout the remainder of the test. This suggests that EAA treatment does not simply produce a static hyperalgesic effect that adds to formalin nociception throughout testing, but rather it shifts the tonic phase of the 
formalin test to an earlier time point. We suggest that these agents accelerate the processes involved in mediating the sensitization in spinal cord, which contributes to the tonic later phase of the formalin test. In this way, endogenous release of EAAs may lead to the development of neuroplasticity in spinal nociceptive neurons following an intense nociceptive stimulus, and lead to the development of persistent nociception, as occurs following formalin injection. Indeed, EAAs have been strongly implicated in other models of neuroplasticity (Collingridge and Bliss, 1987; Cotman and Monaghan, 1988).

Further evidence for a critical role of the NMDA receptor in this ncuroplastic response to formalin is implicated by the finding that formalin nociception is dose-dependently reduced by the selective NMDA receptor antagonists APV and MK-801. Conversely, formalin nociception was unaffected by either the AMPA receptor antagonist CNQX or the metabotropic EAA receptor antagonist AP-3. Furthermore, the inhibition produced by APV or MK-801 was restricted to the intermediate and late phases of the formalin test, suggesting that these agents specifically suppress the development of plasticity contributing to the late phase response rather than producing a generalized analgesic effect. These results are supported by previous findings of Haley et al. (1990), who demonstrated that pretreatment with intrathecal AP-5 or intravenous MK-801 produced a marked inhibition of dorsal horn activity in the late phase after subcutaneous formalin injection, while producing small nonsignificant cffects on activity during the early phase. Thus, both behavioral and electrophysiological experiments indicate that early-phase nociceptive responses are largely unaffected by the NMDA antagonists.

Since NMDA antagonists reduce the slowly developing tonic nociception after formalin injury, but not the immediate response to formalin, it is expected that the NMDA receptor is more critically involved in the production of plasticity, which contributes to persistent nociceptive responses, than it is in the immediate signaling of a brief phasic stimulus. This may explain why NMDA commonly produces hyperalgesia to phasic nociceptive stimuli (Aanonsen and Wilcox, 1986, 1987), but NMDA antagonists are often incapable of producing analgesia in these same tests, at doses that do not affect motor activity (Cahusac et al., 1984; Aanonsen and Wilcox, 1987). Thus, while plastic changes in response to EAA agonists may alter sensitivity to phasic nociceptive tests, the analgesic effects of EAA antagonists would only be detectable in nociceptive tests, such as the formalin test, which involve stimuli that produce a significant sensitization of central nociceptive neurons.

Since the high doses of APV and MK-801 were ineffective in the late phase of the formalin test if administered following the early phase of the formalin response (i.e., $10 \mathrm{~min}$ after formalin), there is evidence that the NMDA receptor is critical to the development of plasticity or sensitization in response to tissue injury, but not to ongoing pain responses after the sensitization has occurred. EAA antagonists may be better viewed as agents that are protective of central sensitization that contributes to persistent pain, rather than as analgesic agents. This view is consistent with the neurophysiological effects of EAAs in the spinal cord. Importantly, it has been shown that NMDA antagonists reduce polysynaptic, more than monosynaptic, excitation in the spinal cord (Davies and Watkins, 1983), and have been shown to block the development of "windup" (Davies and Lodge, 1987; Dickenson and Sullivan, 1987a), which is induced in dorsal horn neurons by repetitive stimulation of C-fibers. In addition, while iontophoretic administration of NMDA pro- duces an enhancement of dorsal horn excitatory responses to natural stimuli, there is a relatively long delay $(1 \mathrm{~min})$ before this effect is seen (Aanonsen et al., 1990).

The present data clearly suggest a critical contribution of EAAs to neuroplasticity and persistent pain following formalin-induced tissue injury. It is expected that an intense activation of C-fiber afferents following formalin injection (Heapy et al., 1987) leads to a fast transmitter-mediated input to spinal projection neurons, which underlies the early-phase responses in the formalin test. Since glutamate is released within spinal cord dorsal horn in response to subcutaneous formalin injection (Skilling et al., 1988) and has been implicated as a possible primary afferent transmitter involved in monosynaptic inputs (Davies and Watkins, 1983), this fast transmitter action may be mediated by glutamate. It is also expected that the depolarization associated with the fast transmitter activation of non-NMDA receptors (possibly the AMPA or kainate receptor) will reduce an $\mathrm{Mg}^{2}$ । blockade of NMDA receptor channels (Mayer et al., 1984; Nowak et al., 1984), and mediate an NMDA-dependent windup in dorsal horn neurons (Dickenson and Sullivan, 1990). The windup effect may be mediated predominantly by aspartate, which is also released within the spinal cord dorsal horn in response to subcutaneous formalin injection (Skilling et al., 1988), and is the major endogenous transmitter acting at the NMDA receptor (Watkins and Evans, 1981). Aspartate has been implicated as a primary candidate for mediating polysynaptic response exerted on spinal projection neurons by excitatory interneurons (Davies and Watkins, 1983).

A repetitive activation of the NMDA receptor by aspartate would cause $\mathrm{Ca}^{2+}$ ions to enter the cell (MacDermott et al., 1986) and may mediate plastic changes within the cell by stimulating $\mathrm{Ca}^{2+} /$ calmodulin-dependent protein kinases (Miller and Kennedy, 1986). Also, studies indicate that metabotropic EAA receptors are coupled to second messengers, such as inositol trisphosphate and diacylglycerol, which stimulate protein kinase C. Thus, it is possible that the formalin stimulus triggers longterm alterations in nociceptive functioning by an NMDA-dependent calcium influx, or stimulation of second messengers coupled with metabotropic EAA receptors, both of which would act through protein kinases to phosphorylate membrane bound proteins. This would alter ion channels and affect synaptic efficiency for a prolonged period of time, and thus may underlic the central sensitization that contributes to the prolonged late phase of the formalin test.

\section{References}

Aanonsen LM, Wilcox GL (1986) Phencyclidine selectively blocks a spinal action of $N$-methyl-D-aspartate in mice. Neurosci Lett 67:191197.

Aanonsen LM, Wilcox GL (1987) Nociceptive action of excitatory amino acids in the mouse: effects of spinally administered opioids, phencyclidine and sigma agonists. J Pharmacol Exp Ther 243:9-19.

Aanonsen LM, Lei S, Wilcox GL (1990) Excitatory amino acid receptors and nociceptive neurotransmission in rat spinal cord. Pain 41:309-322.

Beitel RE, Dubner R (1976) Response of unmyelinated (C) polymodal nociceptors to thermal stimuli applied to monkey's face. J Neurophysiol 39:1160-1175.

Bessou P, Perl ER (1969) Response of cutaneous sensory units with unmyelinated fibers to noxious stimuli. J Neurophysiol 32:1025-1043.

Cahusac PMB, Evans RH, Hill RG, Rodriquez RE, Smith DAS (1984) The behavioral effect of an $N$-methyl-D-aspartate receptor antagonist following application to the lumbar spinal cord of conscious rats. Neuropharmacology 23:719-724.

Coderre TJ, Melzack R (1985) Increased pain sensitivity following 
heat injury involves a central mechanism. Behav Brain Res 15:259262.

Coderre TJ, Vaccarino AL, Melzack R (1990) Central nervous system plasticity in the tonic pain response to subcutaneous formalin injection. Brain Res 535:155-158.

Collingridge CL, Bliss TVP (1987) NMDA receptors - their role in long-term potentiation. Trends Neurosci 10:288-293.

Cook AJ, WoolfCJ, Wall PD, McMahon SB (1987) Dynamic receptive field plasticity in rat spinal dorsal horn following C-primary afferent input. Nature 325:151-153.

Cotman CW, Monaghan DT (1988) Excitatory amino acid neurotransmission: NMDA receptors and Hebb-type synaptic plasticity. Annu Rev Neurosci 11:61-80.

Davies J, Watkins JC (1983) Role of excitatory amino acids receptors in mono- and polysynaptic excitation in the cat spinal cord. Exp Brain Res 49:280-290.

Davies SN, Lodge D (1987) Evidence for involvement of $N$-methylaspartate receptors in "wind-up" of class 2 neurones in the dorsal horn of the rat. Brain Res 424:402-406.

Dickenson AH, Sullivan AF (1987a) Evidence for a role of the NMDA receptor in the frequency dependent potentiation of deep rat dorsal horn nociceptive neurones following $C$ fibre stimulation. Neuropharmacology 26:1235-1238.

Dickenson AH, Sullivan AF (1987b) Subcutaneous formalin-induced activity of dorsal hom neurons in the rat: differential response to an intrathecal opiate administered pre or post formalin. Pain 30:349 360 .

Dickenson AH, Sullivan AF (1990) Differential effects of excitatory amino acid antagonists on dorsal horn nociceptive neurones in the rat. Brain Res 506:31-39.

Dubuisson D, Dennis SG (1977) The formalin test: a quantitative study of the analgesic effects of morphine, meperidine, and brain stem stimulation in rats and cats. Pain 4:161-174.

Haley JE, Sullivan AF, Dickenson AH (1990) Evidence for spinal $N$-methyl-D-aspartate receptor involvement in prolonged chemical nociception in the rat. Brain Res 518:218-226.

Heapy CG, Jamieson A, Russell NJW (1987) Afferent C-fibre and A-delta activity in models of inflammation. Br J Pharmacol 90: $164 \mathrm{P}$.

Hylden JKL, Wilcox GL (1980) Intrathecal morphine in mice: a new technique. Eur J Pharmacol 67:313-316.

Hylden JKL, Nahin RL, Traub RJ, Dubner R (1989) Expansion of receptive fields of spinal lamina $I$ projection neurons in rats with unilateral adjuvant-induced inflammation: the contribution of dorsal horn mechanisms. Pain 37:229-243.

Kenshalo DR Jr, Leonard RB, Chung JM, Willis WD (1979) Responses of primate spinothalamic neurons to graded and to repeated noxious heat stimuli. J Neurophysiol 42:1370-1389.

King AE, Thompson SWN, Urban L, WoolfCJ (1988) An intracellular analysis of amino acid induced excitations of deep dorsal horn neurones in the rat spinal cord slice. Neurosci Lett 89:286-292.
MacDermott AB, Mayer ML, Westbrook GI, Smith SJ, Barker JL (1986) NMDA-receptor activation increases cytoplasmic calcium concentration in cultured spinal cord neurones. Nature 321:519-522.

Mayer ML, Westbrook GL, Guthrie PB (1984) Voltage-dependent block by $\mathrm{Mg}^{2+}$ of NMDA responses in spinal cord neurones. Nature 309:261--263.

Mendell LM (1966) Physiological properties of unmyelinated fiber projections to the spinal cord. Exp Neurol 16:316-332.

Miller RJ (1991) Metabotropic excitatory amino acid receptors reveal their true colors. Trends Pharmacol Sci 12:365-367.

Miller SG, Kennedy MB (1986) Regulation of brain type II Ca ${ }^{2+}$ calmodulin-dependent protein kinase by autophosphorylation: $\mathrm{C}^{2+}$. triggered molecular switch. Cell 44:861-870.

Nowak L, Bregestovski P, Ascher P, Hebert A, Prochiantz A (1984) Magnesium gates glutamate-activated channels in mouse central neurones. Nature 307:462-465.

Papir-Kricheli D, Frey J, Laufer R, Gilon C, Chorev M, Selinger Z, Devor M (1987) Behavioural effects of receptor-specific substance $P$ agonists. Pain 31:263-276.

Perl ER (1976) Sensitization of nociceptors and its relation to sensation. In: Advances in pain research and therapy, Vol 1 (Bonica JJ, Albe-Fessard D, eds), pp 17-28. New York: Raven.

Price DD, Hayes RL, Ruda M, Dubner R (1978) Spatial and temporal transformations of input to spinothalamic tract neurons and their relation to somatic sensations. J Neurophysiol 41:933-946.

Skilling SR, Smullin DH, Larson AA (1988) Extracellular amino acid concentrations in the dorsal spinal cord of freely moving rats following veratridine and nociceptive stimulation. J Neurochem 51:127-132.

Watkins JC, Fvans RH (1981) Fxcitatory amino acid transmitters. Annu Rev Pharmacol Toxicol 21:165-204.

Wheeler-Aceto H, Porreca F, Cowan A (1990) The rat paw formalin test: comparison of noxious agents. Pain 40:229-238.

Woolf CJ (1983) Evidence for a central component of post-injury pain hypersensitivity. Nature 308:686-688.

Woolf CJ, Thumpson SWN (1991) The induction and maintenance of central sensitization is dependent on $N$-methyl-D-aspartic acid receptor activation: implications for post-injury pain hypersensitivity states. Pain 44:293-299.

Woolf CJ, Wall PD (1986) Relative effectiveness of C primary afferent fibers of different origins in evoking a prolonged facilitation of the flexion reflex in the rat. $J$ Neurosci $6: 1433-1442$.

Woolf CJ, Wiesenfeld-Hallin Z (1986) Substance $P$ and calcitonin gene-related peptide synergistically modulate the gain of the nociceptive flexor withdrawal reflex in the rat. Neurosci Lett 66:226-230.

Zar JH (1984) Biostatistical analysis. Englewood Cliffs, NJ: Prentice Hall.

Zieglgansberger W, Herz A (1971) Changes of cutaneous receptive fields of spino-cervical-tract neurones and other dorsal horn neurones by microelectrophoretically administered amino acids. Exp Brain Res 13:111-126. 